\title{
European consensus on core principles and future priorities for geriatric rehabilitation: consensus statement
}

\author{
Stefan Grund ${ }^{1} \cdot$ Adam L. Gordon ${ }^{2} \cdot$ Romke van Balen $^{3} \cdot$ Stefan Bachmann ${ }^{4,5}$. Antonio Cherubini ${ }^{6}$. Francesco Landi . $^{7}$ \\ Andreas E. Stuck ${ }^{5}$. Clemens Becker ${ }^{8}$. Wilco P. Achterberg ${ }^{9} \cdot$ Jürgen M. Bauer ${ }^{1}$. Jos M. G. A. Schols ${ }^{10}$
}

Received: 27 July 2019 / Accepted: 8 November 2019 / Published online: 13 December 2019

(c) The Author(s) 2019

\section{Key summary points}

Aim The consensus statement about core principles and future priorities of geriatric rehabilitation has the aim to help healthcare providers which need strategies to support older people who have experienced functional decline.

Findings Geriatric rehabilitation is now defined in a way that is compatible with existing service models across Europe.

Message This consensus statement can provide a starting point for further development of geriatric rehabilitation.

\begin{abstract}
Purpose In response to the growing recognition of geriatric rehabilitation and to support healthcare providers which need strategies to support older people with frailty who have experienced functional decline, we developed a consensus statement about core principles and future priorities for geriatric rehabilitation.

Methods We used a three-stage approach to establish consensus_-preparation, consensus and review.

Results The consensus statement is grouped under 11 headings from (1) "Definition of GR" to (11) "Effective strategies to develop GR in Europe", which define geriatric rehabilitation in a way that is compatible with existing service models across Europe. Additionally future goals around research and education are highlighted.

Conclusion The definitions of the consensus statement can provide a starting point for those wishing to further develop geriatric rehabilitation in their jurisdiction and help to develop strategic alliances with other specialties, serving as a basis for a pan-European approach to geriatric rehabilitation.
\end{abstract}

Stefan Grund

stefan.grund@bethanien-heidelberg.de

Jos M. G. A. Schols

jos.schols@maastrichtuniversity.nl

https://hsr.mumc.maastrichtuniversity.nl

https://www.LPZ-UM.eu

1 Center for Geriatric Medicine, Agaplesion Bethanien Hospital Heidelberg, Geriatric Center at the Heidelberg University, Rohrbacher Straße 149, 69126 Heidelberg, Germany

2 Division of Medical Sciences and Graduate Entry Medicine, University of Nottingham, Room 4113, Derby Medical School, Royal Derby Hospital, Derby DE22 3NE, UK

3 Department of Public Health and Primary Care, Leiden University Medical Centre, Hippocratespad 2, Postzone VO-P, Postbus 9600, 2300 RC Leiden, The Netherlands

4 Klinik für Rheumatologie und internistische Rehabilitation, Kliniken Valens, Taminaplatz 1, 7317 Valens, Switzerland

5 Department of Geriatrics, Inselspital, Bern University Hospital, University of Bern, Freiburgstrasse 46, 3010 Bern, Switzerland
6 Geriatria, Accettazione Geriatrica e Centro di Ricerca per l'invecchiamento, IRCCS-INRCA, Ancona, Italy

7 Department of Geriatrics, Neurosciences and Orthopedics, Catholic University of the Sacred Heart, L.go F. Vito 8, Rome, Italy

8 Department for Geriatric Medicine and Rehabilitation, Robert-Bosch-Krankenhaus, Auerbachstraße 110, 70376 Stuttgart, Germany

9 Department of Public Health and Primary Care, Leiden University Medical Center, Hippocratespad 21 Postzone V0-P, Room V6-76, Postbus 9600, 2300 RC Leiden, The Netherlands

10 Departments of Health Services Research, Focusing on Value-based Care and Ageing and Family Medicine, Care and Public Health Research Institute (Caphri), Maastricht University, Duboisdomein 30, 6229 GT, P.O. Box 616, 6200 MD, Maastricht, The Netherlands 
Keywords EuGMS · European consensus · Geriatric rehabilitation · Frailty · Functional decline

\section{Introduction}

The Geriatric Rehabilitation (GR) Special Interest Group of the European Geriatric Medicine Society (EuGMS) was established in 2018 in response to the growing recognition of geriatric rehabilitation across member states. Population ageing means that healthcare providers are increasingly challenged by the need to develop strategies to support older people with frailty who have experienced functional decline $[1,2]$. Geriatricians and older persons care physicians need to be ready to lead and advise on the development of such services. To support such work, we present here a consensus statement about the definition of GR, the type of patients who should receive GR and about the core principles and future priorities for GR.

\section{Methods}

We used a three-stage approach to establish consensuspreparation, consensus and review.

The preparation stage comprised two Delphi studies, one about the definition and organisation of GR in Europe [3], and one about the structures for GR across Europe [4]. These are reported in detail elsewhere. The findings were used as the basis for the second consensus stage.

For the consensus stage a group of 11 experts in GR from 5 EUGMS member states (Netherlands, Germany, UK, Switzerland, Italy) were invited to attend a face-to-face meeting in Heidelberg, Germany on the 18th and 19th May, 2019. Each participant was sent the outputs of the structural survey as well as the Delphi exercises and asked to return suggestions on text for a consensus document in advance of the meeting. These suggestions were presented at the meeting and discussed and edited until consensus was achieved.

In the review phase, the text of the consensus document was sent to all members of the EUGMS GR Special Interest Group, comprising representatives from (insert countries here), final comments were invited and approval from the EuGMS Executive Board obtained.

\section{Results}

The consensus statement is grouped under eleven headings: (1) definition of GR; (2) definition of GR patients; (3) resources for GR; (4) GR team structure; (5) rationale and limits of standards and guidelines in GR; (6) rationale and limits of a systematic evaluation system in GR; (7) definition of facilitators and barriers for further development of
GR across Europe; (8) the rehabilitation process, (9) treatment principles, (10) education in GR, (11) effective strategies to develop GR in Europe.

\section{Definition of geriatric rehabilitation}

Geriatric Rehabilitation (GR) is defined as a multidimensional approach of "diagnostic and therapeutic interventions, the purpose of which is to optimise functional...," capacity, promote activity and preserve functional reserve and social participation "in older people with disabling impairments." This definition is based upon the ICF-framework of the $\mathrm{WHO}$ and the WHO rehabilitation cycle. It focuses upon patient-centred goals which reflect individual preferences established through co-operation with the patient and his or her caregivers.

Depending on different national policies, reimbursement structures and local availability, geriatric rehabilitation is offered in widely different settings. Moreover, it can be ambulatory, hospital-based or nursing home-based.

\section{Definition of geriatric rehabilitation patient}

GR is recommended for patients affected by multimorbidity and geriatric syndromes, who have the potential to improve their experience and/or outcome of functional performance. They should be participants in the rehabilitation process. Chronological age, place of residence and the presence of cognitive impairment should not be used to exclude patients from GR, but might have an impact on tailoring rehabilitation to specific patient`s needs.

\section{Resources for geriatric rehabilitation}

The available resources for GR with respect to facilities and beds vary a lot between the EuGMS member states. In most countries the available resources are insufficient, resulting in unmet needs. Rising demand reflecting demographic change, the ageing in place policy and development in treatments for chronic diseases across Europe means that an increase in available capacity across all forms of GR is required. Urgent attention should be given to mapping intrinsic capacity and responding to projected GR needs across all member countries.

\section{Geriatric rehabilitation team structure}

The structure and composition of the geriatric rehabilitation team are very different in the individual EuGMS member states. Ideally a GR-skilled physician, like a geriatrician, 
nursing home physician or other doctor with specialist training in care of older people, should lead the team.

The other professionals consistently included in the multidisciplinary core team are skilled nurses*, a physiotherapist, occupational therapist and social worker. In some countries this extends to include a psychologist, a pharmacist, a dietician and a speech therapist. Services should be designed to ensure that patients can access all relevant professional expertise when required.

*The word nurse also includes nurses of different levels.

\section{Rationale and limits of standards and guidelines in GR}

To ensure standardisation of treatment quality in GR across the EuGMS member states, the development and implementation of national and international standards and guidelines specific to GR are necessary. Research to provide the basis for high-level uniform treatment standards and international guidelines in GR should be prioritized and funded.

\section{Rationale and limits of a systematic evaluation system in GR}

There is currently no universally agreed approach regarding the use of indicators to drive quality assurance and improvement in GR. However, some countries have individual measures in place. We need to learn from these existing initiatives and increase health service research activities to build an agreed and feasible set of structure, process and outcome metrics for geriatric rehabilitation across Europe.

\section{Definition of facilitators and barriers for further development of GR across Europe}

GR has a long tradition in some European countries but has not yet been established in every EuGMS member state. In this respect some barriers have recently been reported. These include a lack of a policy framework for GR, a lack of available geriatric medicine resource, and determination of rehabilitation pathways based upon financial considerations rather than patients' needs.

The accumulated knowledge about barriers and facilitators to the implementation of GR requires to be collated and shared. This will enable the development and establishment of geriatric rehabilitation services across the EuGMS member states.

\section{The rehabilitation process}

GR services should be configured so that ambulatory and inpatient settings are linked. Inpatient GR can be located in hospitals, rehabilitation centres or nursing homes.
Following an acute event or functional decline due to chronic conditions, rehabilitation should start as soon as possible. It should commence in the setting closest to the patient and best able to meet his or her needs. The admission to each setting should be based upon clinical criteria. Seamless care should enable patients to move between different geriatric rehabilitation settings based upon progress and need.

A common approach to rehabilitation should be adopted by all geriatric rehabilitation settings. Comprehensive Geriatric Assessment (CGA) incorporating the perspective of the patient and informal caregivers should be used within a framework of shared decision-making to structure a tailored rehabilitation plan. This should be goal-orientated with appropriate priority given to the preferences of the patient. Goals should be measurable and time-specific.

The plan should be reviewed at regular team meetings. Discharge planning should be interdisciplinary and commence early, if possible from the point of admission.

\section{Treatment principles}

Rehabilitation should focus on minimising activity limitation and maximising societal participation, even in situations where body structure and function cannot be restored to premorbid levels. This may require the use of aids, appliances, technical and environmental adaptations. Rehabilitation programmes should encompass the psychosocial components of health and wellbeing.

Therapeutic intensity has to be tailored to the need of the individual patient and often needs to accommodate the reduced capabilities of geriatric rehabilitation patients.

Within the broad context of geriatric rehabilitation, patients present with a wide range of specific conditions. Some of these may have highly specific rehabilitation needs, for example stroke, Parkinson's disease, hip fracture, amputation, COPD and chronic heart failure.

\section{Education in geriatric rehabilitation}

To further standardise provision of GR across Europe, it is important to agree on core competencies for geriatricians and nursing home physicians and to ensure these are delivered as part of speciality training. Given that GR is interdisciplinary, the EuGMS could play a leading role to establish and support specific training in geriatric rehabilitation for relevant healthcare professions across member states.

To establish an appropriate foundation knowledge and skills for all medical practitioners we recommend inclusion of content about GR in undergraduate medical curricula. 


\section{Effective strategies to develop geriatric rehabilitation in Europe}

All EuGMS member states should formally recognise the establishment and maintenance of high-quality GR as a priority. This has to be accompanied by structural, organisational and financial resources, to allow access for all people in need of GR.

Work is required to establish the cost-benefit of GR programmes across EuGMS member states. Insights should be used to further standardise the delivery of care to ensure maximum cost-benefit allowing for individual health and social care systems. This should be a research priority.

Research should consider the impact of GR when provided in ambulatory, hospital and nursing home settings. We need to understand which patient groups are best served by each approach.

There is a need to transfer GR awareness and knowledge to other medical specialties involved in the care of older people. Working relationships must be built with other specialist societies, for example those representing rehabilitation physicians, general practitioners, neurologists and surgeons, to develop shared training initiatives and guidelines.

To establish whether and how GR can play a role in preventing and treating functional decline in specific conditions such as stroke, Parkinson's, multiple sclerosis and patients with cancer, further work is needed.

\section{Conclusion}

We have, in this document, defined geriatric rehabilitation in a way that is compatible with existing service models across Europe. It is clear that, in many parts of the continent, GR is a sub-specialty which is under development, or is yet to be recognised. The definitions here can provide a starting point for those wishing to further develop geriatric rehabilitation in their jurisdiction. Additionally, this paper highlights future goals around research, education and the development of strategic alliances with other specialties, which can provide the basis of a pan-European approach to geriatric rehabilitation. The ambition now is to develop a working plan to support such work. Interested colleagues from across the continent are encouraged to join us.

Acknowledgements The authors would like to thank Finbarr Martin (Past President of the EuGMS), Stefania Maggi (President of the EuGMS) and Mirko Petrovic (Academic Director of the EuGMS) (EuGMS Executive Board) for giving the opportunity to undertake this consensus process as well as for reviewing, editing and approving the manuscript. We have to thank all member of the new founded EuGMS Special Interest Group (SIG) on GR for giving their comments to the manuscript. Furthermore the authors would like to thank Benedetta
Bellotti (EuGMS secretariat) for their support throughout the whole consensus process and especially in organisation of the consensus meeting in Heidelberg.

\section{Compliance with ethical standards}

Conflict of interest This work was financially supported by the EuGMS. AC has received consulting and speaker fees from Nestlè. SG, ALG, RvB, SB, AS, CB, WA, JMB, JMGAS have no conflict of interest to declare.

Ethical approval This article does not contain any studies with human participants performed by any of the authors.

Informed consent Informed consent is not required for the present study in any home country of the author and co-authors.

Open Access This article is distributed under the terms of the Creative Commons Attribution 4.0 International License (http://creativeco mmons.org/licenses/by/4.0/), which permits unrestricted use, distribution, and reproduction in any medium, provided you give appropriate credit to the original author(s) and the source, provide a link to the Creative Commons license, and indicate if changes were made.

\section{References}

1. de Jong B, Wynia K, Geluk-Bleumink A (2018) Ageing Better in the Netherlands. In: D'Onofrio G, Sancarlo D, Greco A (eds) Gerontology. IntechOpen, London, pp 101-111

2. De Donder L, Smetcoren AS, Schols JMGA, van der Vorst A, Dierckx E, D-SCOPE Consortium (2019) Critical reflections on the blind sides of frailty in later life. J Aging Stud 49:66-73

3. van Balen R, Gordon AL, Schols JMGA, Drewes YM, Achterberg WP (2019) What is geriatric rehabilitation and how should it be organized? A Delphi study aimed at reaching European consensus. Eur Geriatr Med 10:977-987. https://doi. org/10.1007/s41999-019-00244-7

4. Grund S, van Wijngaarden J, Gordon AL, Schols JMGA, Bauer JM (2019) EUGMS survey on structures of geriatric rehabilitation across Europe. Eur Geriatr Med. https://doi.org/10.1007/ s41999-019-00273-2

\section{Definition of GR}

5. Achterberg WP, Cameron ID, Bauer JM, Schols JM (2019) Geriatric rehabilitation: state of the art and future priorities. JAMDA 20:396-398

6. Bachmann S, Finger C, Huss A et al (2010) Inpatient rehabilitation specifically designed for geriatric patients: systematic review and meta-analysis of randomized controlled trials. BMJ 340:c1718

7. Beard J, Officer A, Cassels A (2015) World report on ageing and health. World Health Organisation, Geneva

8. Beard JR, Officer A, de Carvalho IA, Sadana R, Pot AM, Michel JP et al (2016) The world report on ageing and health: a policy framework for healthy ageing. Lancet (London, England) 387(10033):2145-2154

9. Kane RL, Jette AM, Hamilton BB, Liang MH, Whiteneck G, Kramer AM, Fuhrer MJ, Keith RA, Materson R, Stason WB, 
Bergstrom N, Duncan P, Laouri M, Johnston MV, Stineman MG, Morrison MH, Morris JN, Leiter P, Markello S, Lohr KN (1997) Boston working group on improving health care outcomes through geriatric rehabilitation. Med Care 35:JS4-JS20

10. Cameron ID, Kurrle SE (2015) Frailty and rehabilitation. Interdiscip Top Gerontol Geriatr 41:137-150

11. Stucki G, Ewert T, Cieza A (2003) Value and application of the ICF in rehabilitation medicine. Disabil Rehabil 25:628-634

12. Stucki G, Cieza A, Melvin J (2007) The international classification of functioning, disability and health (ICF): a unifying model for the conceptual description of the rehabilitation strategy. J Rehabil Med 39:279-285

13. Stucki G, Melvin J (2007) The international classification of functioning, disability and health: a unifying model for the conceptual description of the rehabilitation strategy. J Rehabil Med 39:286-292

14. WHO Expert Committee on Disability Prevention and Rehabilitation (1981) Disability prevention and rehabilitation. World Health Organ Tech Rep Ser 668:1-39

\section{Definition of GR patients}

15. Achterberg WP, Cameron ID, Bauer JM, Schols JM (2019) Geriatric rehabilitation: state of the art and future priorities. JAMDA 20:396-398

16. Dutzi I, Schwenk M, Kirchner M, Bauer JM, Hauer K (2017) Cognitive change in rehabilitation patients with dementia: prevalence and association with rehabilitation success. J Alzheimers Dis 60(3):1171-1182. https://doi.org/10.3233/JAD-170401

17. Hauer K, Schwenk M, Zieschang T et al (2012) Physical training improves motor performance in people with dementia: a randomized controlled trial. J Am Geriatr Soc 60(1):8-15. https ://doi.org/10.1111/j.1532-5415.2011.03778.x

18. National Association for Rehabilitation (Germany)-Guidelines: geriatrics. https://www.bar-frankfurt.de/fileadmin/dateiliste/ publikationen/arbeitshilfen/downloads/Arbeitshilfe_Geriatrie. pdf. Accessed 15 July 2019

19. van Balen R, Gordon AL, Schols JMGA, Drewes YM, Achterberg WP (2019) What is geriatric rehabilitation and how should it be organized? A Delphi study aimed at reaching European consensus. Eur Geriatr Med 10:977-987. https://doi. org/10.1007/s41999-019-00244-7

20. Grund S, van Wijngaarden J, Gordon AL, Schols JMGA, Bauer JM (2019) EUGMS survey on structures of geriatric rehabilitation across Europe. Eur Geriatr Med. https://doi.org/10.1007/ s41999-019-00273-2

21. Toba K, Nakamura Y, Endo $\mathrm{H}$ et al (2014) Intensive rehabilitation for dementia improved cognitive function and reduced behavioral disturbance in geriatric health service facilities in Japan. Geriatr Gerontol Int 14(1):206-211. https://doi. org/10.1111/ggi.12080

22. Geriatrie B (2010) "White book geriatrics: Medical service for geriatric patients: structure and requirements". Weißbuch Geriatrie: die Versorgung geriatrischer Patienten: Struktur und Bedarf. Kohlhammer, Stuttgart

\section{Resources for GR}

23. Duursma S, Castleden M, Cherubini A, Cruz-Jentoft A, Pitkälä K, Rainfray M, Sieber C, Sinclair A, European Union Geriatric Medicine Society (2004) European Union Geriatric Medicine Society. Position Statement on Geriatric Medicine and the provision of health care services to older people. J Nutr Health Aging 8(3):190-195

24. Press release Nr. 464 from 07.11.2006 (destatis) In the year 2050 doubled 60-aged than newborn. https://web.archive.org/ web/20070913013445/http://www.destatis.de/jetspeed/ portal/cms/Sites/destatis/Internet/DE/Presse/pm/2006/11/ PD06_464_12421,templateId=renderPrint.psml. Accessed 29 June 2019

25. Rehabilitation Report 2018: German pension insurance. https ://www.deutsche-rentenversicherung.de/Allgemein/de/Inhalt/6_ Wir_ueber_uns/03_fakten_und_zahlen/03_statistiken/02_stati stikpublikationen/02_rehabericht_2018.pdf?__blob=publicatio nFile \&v $=2$. Accessed 29 June 2019

26. Grund S, van Wijngaarden J, Gordon AL, Schols JMGA, Bauer JM (2019) EUGMS survey on structures of geriatric rehabilitation across Europe. Eur Geriatr Med. https://doi.org/10.1007/ s41999-019-00273-2

\section{GR team structure}

27. van Balen R, Gordon AL, Schols JMGA, Drewes YM, Achterberg WP (2019) What is geriatric rehabilitation and how should it be organized? A Delphi study aimed at reaching European consensus. Eur Geriatr Med 10:977-987. https://doi. org/10.1007/s41999-019-00244-7

28. Grund S, van Wijngaarden J, Gordon AL, Schols JMGA, Bauer JM (2019) EUGMS survey on structures of geriatric rehabilitation across Europe. Eur Geriatr Med. https://doi.org/10.1007/ s41999-019-00273-2

\section{Rationale and limits of standards and guidelines in GR}

29. Example for a national Triage Guideline for Inpatient Geriatric Rehabilitation (Canada): http://www.gtarehabnetwork.ca/uploa ds/File/tools/Inpatient-Geriatric-RehabTriage-Guideline.pdf. Accessed 29 June 2019

30. Example for a national triage instrument (Dutch). https://www. verenso.nl/dossiers/financiering_producten/geriatrische-reval idatiezorg/standpunten-en-producten-grz/triage-instrument-grz. Accessed 29 June 2019

31. van Balen R, Gordon AL, Schols JMGA, Drewes YM, Achterberg WP (2019) What is geriatric rehabilitation and how should it be organized? A Delphi study aimed at reaching European consensus. Eur Geriatr Med 10:977-987. https://doi.org/10.1007/s4199 9-019-00244-7

32. Grund S, van Wijngaarden J, Gordon AL, Schols JMGA, Bauer JM (2019) EUGMS survey on structures of geriatric rehabilitation across Europe. Eur Geriatr Med. https://doi.org/10.1007/s4199 9-019-00273-2

\section{Rationale and limits of a systematic evaluation system in GR}

33. van Balen R, Gordon AL, Schols JMGA, Drewes YM, Achterberg WP (2019) What is geriatric rehabilitation and how should it be organized? A Delphi study aimed at reaching European consensus. Eur Geriatr Med 10:977-987. https://doi.org/10.1007/s4199 9-019-00244-7

34. Grund S, van Wijngaarden J, Gordon AL, Schols JMGA, Bauer JM (2019) EUGMS survey on structures of geriatric rehabilitation 
across Europe. Eur Geriatr Med. https://doi.org/10.1007/s4199 9-019-00273-2

\section{Definition of facilitators and barriers for further development of GR across Europe}

35. Grund S, van Wijngaarden J, Gordon AL, Schols JMGA, Bauer JM (2019) EUGMS survey on structures of geriatric rehabilitation across Europe. Eur Geriatr Med. https://doi.org/10.1007/s4199 9-019-00273-2

\section{The rehabilitation process}

36. National Association for Rehabilitation (Germany)-Guidelines: geriatrics. https://www.bar-frankfurt.de/fileadmin/dateiliste/publi kationen/arbeitshilfen/downloads/Arbeitshilfe_Geriatrie.pdf. Accessed 29 June 2019

37. van Balen R, Gordon AL, Schols JMGA, Drewes YM, Achterberg WP (2019) What is geriatric rehabilitation and how should it be organized? A Delphi study aimed at reaching European consensus. Eur Geriatr Med 10:977-987. https://doi.org/10.1007/s4199 9-019-00244-7

38. Grund S, van Wijngaarden J, Gordon AL, Schols JMGA, Bauer JM (2019) EUGMS survey on structures of geriatric rehabilitation across Europe. Eur Geriatr Med. https://doi.org/10.1007/s4199 9-019-00273-2

\section{Treatment principles}

39. Achterberg WP, Cameron ID, Bauer JM, Schols JM (2019) Geriatric rehabilitation: state of the art and future priorities. JAMDA 20:396-398

40. Bachmann S, Finger C, Huss A et al (2010) Inpatient rehabilitation specifically designed for geriatric patients: systematic review and meta-analysis of randomized controlled trials. BMJ 340:c1718

41. Cameron ID (2005) Coordinated multidisciplinary rehabilitation after hip fracture. Disabil Rehabil 27(18-19):1081-1090

42. DIMI (2005) International classification of functioning, disability and health (ICF). WHO, Geneve

43. National Association for Rehabilitation (Germany)-Guidelines: geriatrics. https://www.bar-frankfurt.de/fileadmin/dateiliste/publi kationen/arbeitshilfen/downloads/Arbeitshilfe_Geriatrie.pdf. Accessed 29 June 2019
44. van Balen R, Gordon AL, Schols JMGA, Drewes YM, Achterberg WP (2019) What is geriatric rehabilitation and how should it be organized? A Delphi study aimed at reaching European consensus. Eur Geriatr Med 10:977-987. https://doi.org/10.1007/s4199 9-019-00244-7

45. Grund S, van Wijngaarden J, Gordon AL, Schols JMGA, Bauer JM (2019) EUGMS survey on structures of geriatric rehabilitation across Europe. Eur Geriatr Med. https://doi.org/10.1007/s4199 9-019-00273-2

46. Stroke Trialist's Collaboration (1997) Collaborative systematic review of the randomized trials of organized inpatient (stroke unit) care after stroke. BMJ 314:1151-1159

47. Wells JL, Seabrook JA, Stolee P et al (2003) State of the art in geriatric rehabilitation. Part I: review of frailty and comprehensive geriatric assessment. Arch Phys Med Rehabil 84:890-897

48. Wells JL, Seabrook JA, Stolee P et al (2003) State of the art in geriatric rehabilitation. Part II: clinical challenges. Arch Phys Rehabil 84:898-903

\section{Education in GR}

49. van Balen R, Gordon AL, Schols JMGA, Drewes YM, Achterberg WP (2019) What is geriatric rehabilitation and how should it be organized? A Delphi study aimed at reaching European consensus. Eur Geriatr Med 10:977-987. https://doi.org/10.1007/s4199 9-019-00244-7

50. Grund S, van Wijngaarden J, Gordon AL, Schols JMGA, Bauer JM (2019) EUGMS survey on structures of geriatric rehabilitation across Europe. Eur Geriatr Med. https://doi.org/10.1007/s4199 9-019-00273-2

\section{Effective strategies to develop GR in Europe}

51. Grund S, van Wijngaarden J, Gordon AL, Schols JMGA, Bauer JM (2019) EUGMS survey on structures of geriatric rehabilitation across Europe. Eur Geriatr Med. https://doi.org/10.1007/s4199 9-019-00273-2

Publisher's Note Springer Nature remains neutral with regard to jurisdictional claims in published maps and institutional affiliations. 